\title{
PREVALENCE OF NUTRITIONAL DEFICIENCIES AMONG OF THE RURAL SCHOOL GOING CHILDREN OF RAJAHMUNDRY DISTRICT IN ANDHRA PRADESH.
}

T. V. Ramesh, S. K. Mishra, Sipra Komal Jena, N. Lakshman Rao

\author{
1. Professor. Department of Paediatrics, GSL Medical College, Rajahmundry, Andhrapradesh. \\ 2. Professor \& HOD. Department of Community Medicine, GSL Medical College, Rajahmundry, \\ Andhrapradesh. \\ 3. Professor. Department of Community Medicine, GSL Medical College, Rajahmundry, Andhrapradesh. \\ 4. Assistant Professor. Department of Statistics, Regional Institute of Medical Sciences, Ongole, \\ Andhrapradesh
}

\section{CORRESPONDING AUTHOR:}

Dr. T. V. Ramesh,

Professor, Department of Paediatrics,

G.S.L. Medical College,

Rajahmundry, Andhra Pradesh- 533296.

E-mail: drtvr2010@gmail.com

\begin{abstract}
The first Millennium Development Goal calls for the eradication of extreme poverty and hunger, and its achievement is crucial for national progress and development. Nearly one third of the under five children (about 195 million) in the developing world are either underweight or stunted ${ }^{1}$. In developing countries about $40 \%$ of preschool children are estimated to be anaemic ${ }^{2}$. Due to micronutrient deficiencies, one million children die before the age of five and 100,000 infants are born with preventable physical defects each year ${ }^{3}$. Malnutrition is a process whose consequences are often extended not only in later life, but also into future generations. The present study was undertaken to find out the prevalence of under nutrition in rural schools around Rajahmundry, East Godavari District of Andhra Pradesh. Total 337 students (between 6 to 10 years) were examined for height, weight and for micronutrient deficiency in the form of Iron \& Vitamin A deficiency. Undernutrition was found to be $19 \%$ (Grade II), $6 \%$ (Grade III) and 1\% (Grade IV). Clinical features of iron deficiency were found among 36\% school children and Vitamin deficiency was found among 3\% of children.
\end{abstract}

KEY WORDS: Under nutrition, rural India, school going children

INTRODUCTION: Maternal and child under nutrition contributes to 3.5 million deaths every year, and accounts for $11 \%$ of total global Disability Adjusted Life Years (DALYs) that equates to lost years of healthy life ${ }^{4}$. According to National Family Health Survey (NFHS-3), 40\% of Indian children under the age of three are under weight, $45 \%$ are stunted, and $23 \%$ are wasted 5 . Comparable figures for NFHS-2 (1998-1999) were 43\%, 51\% \& 20\% respectively. In growing children, malnutrition affects intelligence and physical capacity. These in turn reduces productivity, slows economic growth and aggravates poverty. The economic cost of malnutrition is very high6. The proportion of children who are stunted or underweight increases rapidly with child's age. During first six months of life, when most babies are breastfed, $20-30 \%$ of children are already malnourished. By 18-23 months when many children are being weaned from breast milk, $30 \%$ of children are severely stunted and one fifth is severely underweight ${ }^{7}$. This clearly shows that the onset of malnutrition in Indian children occurs very early in their life. The prevalence of underweight children in India is highest in the 
world. Child malnutrition in school going children is responsible for $22 \%$ of the country's burden of diseases ${ }^{8}$. Though the aggregated level of under nutrition is shockingly high, the picture is further magnified by the significant inequalities across the states and socioeconomic groups and location with those living in rural area being worst affected ${ }^{9}$. Deficiencies of key vitamins and minerals continue to be pervasive and they overlap considerably with problem of general under nutrition ${ }^{6}$. The age of 5 to 15 years is a period of transition between childhood and adulthood which occupies a crucial position in the life of human beings. This period is characterized by an exceptionally rapid rate of growth. School provides the most effective and efficient way to reach large portion of the school age population ${ }^{10}$.

The present study was undertaken to find out the prevalence of under nutrition in rural schools around Rajahmundry, East Godavari District of Andhra Pradesh and to compare the status with the variables.

MATERIALS \& METHODS: A Community based cross sectional study was carried out from $1^{\text {st }}$ July - 31 $1^{\text {th }}$ August 2012 in the rural field practice area of GSL Medical College in Rajanagaram mandal at East Godavari district. The rural field practice area was further divided into three identical zones based on the population and the name of villages. One representative school from each zone was randomly selected. In all the three schools, total 337 children between 6 to 10 years (from 1 st to 7 th standard) were randomly selected from the attendance register. Those children who could not be contacted after three successive visits were excluded from the study. Information regarding age, sex, religion, parent's occupation, and income was collected from the school records. To avoid inter observer error, the anthropometric measurements were recorded by two different trained personnel one for reading weight \& another for height. Intra observer error was within acceptable limits for both height and weight measurements. Height was measured by wall mounted fibre glass tape with the least count of 0.5 . The tape was mounted accurately on the wall perpendicular to the floor. Care was taken that the floor was levelled properly and the wall was also even. Weight measurement was taken by standardized digital weighing scale with the least count of 0.1 . Both the equipment was standardized at regular intervals. A pretested semi structured questionnaire was used to record all information. In the rural area, invasive technique of blood collection is always not feasible so clinical signs and symptoms were studied for micronutrient deficiencies like iron, vitamin A using the WHO criteria ${ }^{11}, 12 \& 13$. To evaluate iron deficiency, swollen and red tongue, brittle nails, pale skin, angular stomatitis, easy fatigueness and pallor signs were assessed. To evaluate Vitamin A deficiency conjunctival xerosis, bitot spot, corneal ulceration, nyctolpia, corneal Xerosis, corneal scar, eye infection was assessed. Under nutrition was classified based on IAP classification of weight for age percentage i.e. normal $(80-100 \%)$, grade I $(<80 \%)$, grade II $(<70 \%)$, grade III $(<60 \%)$ and grade IV $(<50 \%)$ [A prefix $\mathrm{K}$ is added to denote the presence of edema] ${ }^{14}$.

Approval for the study was obtained from the institutional ethical committee. Consent to conduct the survey on the student was obtained from the parents through the school authorities. Verbal consent was also taken from the children after demonstrating and explaining the procedure. All statistical analyses were performed using SPSS software trial Version 16.0 and MS-Excel 2007. Fisher's exact test was used to examine differences with categorical variables. Values were presented as mean $( \pm S D)$. We used Students t-test to compare the different groups. Pearson correlation coefficient was calculated to explore the relationships between the measured parameters. For all statistical analyses, $\mathrm{P}<0.05$ was considered statistically significant. Study variables in this study was taken as age, sex, height, and weight 
OBSERVATION \& RESULTS: There was about 21\% absenteeism in the school. Out of total 337 children who participated in this study, girls outnumbered boys (Table 1). Majority of school students were Hindu (71\%) and belongs to a monthly family income bracket of 4000 to 8000 $(66 \%)$.

Table 1: Distribution of socio demographic characteristic of the Study participants

\begin{tabular}{|l|l|l|l|l|}
\hline Variables & Parameters & boys $(\mathrm{n}=153)$ & girls $(\mathrm{n}=184)$ & total $(\mathrm{n}=337)$ \\
\hline Religion & Hindu & $102(67 \%)$ & $138(75 \%)$ & $240(71 \%)$ \\
\cline { 2 - 5 } & Muslim & $6(4 \%)$ & $2(1 \%)$ & $8(3 \%)$ \\
\cline { 2 - 5 } & Christian & $45(29 \%)$ & $44(24 \%)$ & $89(26 \%)$ \\
\hline Caste & General & $62(40 \%)$ & $73(40 \%)$ & $135(40 \%)$ \\
\cline { 2 - 5 } & SC & $33(22 \%)$ & $28(15 \%)$ & $61(18 \%)$ \\
\cline { 2 - 5 } & ST & $10(7 \%)$ & $16(9 \%)$ & $26(8 \%)$ \\
\cline { 2 - 5 } income & OBC & $48(31 \%)$ & $67(36 \%)$ & $115(34 \%)$ \\
\hline & $2000-4000$ & $24(16 \%)$ & $36(20 \%)$ & $60(18 \%)$ \\
\cline { 2 - 5 } & $>4000-6000$ & $76(50 \%)$ & $54(29 \%)$ & $130(39 \%)$ \\
\cline { 2 - 5 } & $>6000-8000$ & $34(22 \%)$ & $57(31 \%)$ & $91(27 \%)$ \\
\cline { 2 - 5 } & $>8000-10000$ & $17(11 \%)$ & $25(14 \%)$ & $42(12 \%)$ \\
\cline { 2 - 5 } & Above 10000 & $2(1 \%)$ & $12(6 \%)$ & $14(4 \%)$ \\
\hline
\end{tabular}

Table 2: Comparison of weights \& heights as per age and sex

\begin{tabular}{|c|c|c|c|c|c|c|c|c|}
\hline SEX & $\mathrm{N}$ & $\begin{array}{l}\text { AGE } \\
\text { (in Years) }\end{array}$ & $\begin{array}{l}\text { MEAN } \\
\text { WEIGHT }\end{array}$ & SD & P VALUE & MEAN HEIGHT & SD & P VALUE \\
\hline Girls & 46 & \multirow{2}{*}{5} & 16.457 & 2.4536 & \multirow{2}{*}{0.165} & 109.000 & 7.4371 & \multirow{2}{*}{0.05} \\
\hline Boys & 43 & & 17.151 & 2.2295 & & 111.872 & 6.0975 & \\
\hline Girls & 37 & \multirow{2}{*}{7} & 17.757 & 2.2504 & \multirow{2}{*}{$0.002^{*}$} & 114.581 & 6.3119 & \multirow{2}{*}{0.227} \\
\hline Boys & 28 & & 20.414 & 3.8555 & & 116.804 & 7.8955 & \\
\hline Girls & 33 & \multirow[t]{2}{*}{8} & 21.970 & 3.9881 & \multirow{2}{*}{0.143} & 122.424 & 6.3984 & \multirow{2}{*}{0.934} \\
\hline Boys & 21 & & 20.476 & 2.8700 & & 122.571 & 6.3527 & \\
\hline Girls & 26 & \multirow{2}{*}{9} & 23.038 & 2.7200 & \multirow{2}{*}{0.579} & 124.058 & 6.7117 & \multirow{2}{*}{0.305} \\
\hline Boys & 31 & & 23.468 & 3.0847 & & 125.710 & 5.3351 & \\
\hline Girls & 42 & \multirow{2}{*}{10} & 25.333 & 4.8056 & \multirow{2}{*}{0.508} & 129.393 & 7.0620 & \multirow{2}{*}{0.605} \\
\hline Boys & 30 & & 26.050 & 4.0351 & & 130.300 & 7.6119 & \\
\hline
\end{tabular}

A comparison between the anthropometric parameters (Table 2) i.e. weight with age and sex showed that there was no significance difference ( $p>0.05$ ) in weights between boys and girls among different ages. Similarly a comparison with height showed that there was no significance difference $(p>0.05)$ in heights between boys and girls among different ages. 
Table 3: Correlation coefficient between heights and weights

\begin{tabular}{|l|l|l|l|}
\hline AGE & N & r VALUE & Type of correlation \\
\hline 6 & 89 & 0.813 & +ve \\
\hline 7 & 65 & 0.583 & +ve \\
\hline 8 & 54 & 0.689 & +ve \\
\hline 9 & 57 & 0.548 & +ve \\
\hline 10 & 72 & 0.612 & +ve \\
\hline
\end{tabular}

In all age groups both height and weight showed a positive correlation (Table 3)

Table 4: Distribution of wasting as per sex

\begin{tabular}{|c|c|c|c|c|c|}
\hline SEX & NORMAL & MILD & MODERATE & SEVERE & P VALUE \\
\hline Boys & $\begin{array}{l}103 \\
(44 \%)\end{array}$ & $\begin{array}{l}39 \\
(51 \%)\end{array}$ & $\begin{array}{l}8 \\
(47 \%)\end{array}$ & $\begin{array}{l}3 \\
(34 \%)\end{array}$ & \multirow{3}{*}{0.603} \\
\hline Girls & $\begin{array}{l}132 \\
(56 \%)\end{array}$ & $\begin{array}{l}37 \\
(49 \%)\end{array}$ & $\begin{array}{l}9 \\
(53 \%)\end{array}$ & $\begin{array}{l}6 \\
(66 \%)\end{array}$ & \\
\hline Total & $\begin{array}{l}235 \\
(100 \%)\end{array}$ & $\begin{array}{l}76 \\
(100 \%)\end{array}$ & $\begin{array}{l}17 \\
(100 \%)\end{array}$ & $\begin{array}{l}9 \\
(100 \%)\end{array}$ & \\
\hline
\end{tabular}

Sexwise distribution of wasting was not found to be significantly ( $p>0.05)$ associated with the categorization of nutrition. Severity of wasting was found to be more in girls compared to boys (Table 4)

Table 5: Distribution of stunting as per sex

\begin{tabular}{|l|l|l|l|l|l|}
\hline \multirow{2}{*}{ SEX } & NORMAL & MILD & MODERATE & SEVERE & \multirow{2}{*}{ P VALUE } \\
\cline { 1 - 5 } Boys & $\begin{array}{l}31 \\
(48 \%)\end{array}$ & $\begin{array}{l}44 \\
(47 \%)\end{array}$ & $\begin{array}{l}41 \\
(44 \%)\end{array}$ & $\begin{array}{l}37 \\
(44 \%)\end{array}$ & \\
\cline { 1 - 4 } Girls & $\begin{array}{l}34 \\
(52 \%)\end{array}$ & $\begin{array}{l}50 \\
(53 \%)\end{array}$ & $\begin{array}{l}53 \\
(56 \%)\end{array}$ & $\begin{array}{l}47 \\
(56 \%)\end{array}$ & \multirow{2}{*}{0.9411} \\
\cline { 1 - 4 } Total & $\begin{array}{l}65 \\
(100 \%)\end{array}$ & $\begin{array}{l}94 \\
(100 \%)\end{array}$ & $\begin{array}{l}94 \\
(100 \%)\end{array}$ & $\begin{array}{l}84 \\
(100 \%)\end{array}$ & \\
\hline
\end{tabular}

Sexwise distribution of stunting (Table 5) showed that sex was not significantly $(p>0.05)$ associated with categorization of nutrition. Severity of stunting was found is more in girls compared to boys.

Table 6: Micro nutrient deficiency among the school children

\begin{tabular}{|l|l|l|l|}
\hline & & & \\
\hline & Bicronutrient Deficiency & Girls (184) & Total (337) \\
\hline & 64 & 57 & 121 \\
Iron Deficiency Anaemia (IDA) & $(42 \%)$ & $(31 \%)$ & $(36 \%)$ \\
\hline & 6 & 4 & 10 \\
Vitamin A Deficiency (VAD) & $(4 \%)$ & $(2 \%)$ & $(3 \%)$ \\
\hline
\end{tabular}


Estimation of micronutrient deficiency suggested that Iron \& Vitamin A deficiency was there among 36\% and 3\% children respectively (Table 6).

Under nutrition was estimated as Normal - 158 (47 \%), Grade I - 92 (27\%), Grade II - 64 (19\%), Grade III - 20 (6 \%) \& Grade IV - 3 (1\%).

DISCUSSION: Most of the studies in under nutrition are undertaken in under 5 years of children. Our study was undertaken in primary school going children. Our study showed that a large proportion of children in rural areas are still significantly undernourished. Out of 337 children we surveyed we found that there is a declining trend in severe undernutrition (severe malnutrition is only 1\%). In spite of marked decline in severe undernutrition, there is not much decrease in mild to moderate undernutrion i.e. mild malnutrition in $27 \%$ and moderate malnutrition in 19\%. In addition micronutrient deficiency like iron deficiency anaemia is still widely prevailing. Due to wide practice of giving vitamin A prophylaxis in community health programs there is good amount decrease in the prevalence of vitamin A deficiency was noticed (3\%).

School children are at risk population for nutritional deficiency disorders but little attention is paid towards this age group in terms of quality of life and nutritional disorders. Malnutrition is common among school children and is usually coupled with Iron and other micronutrient deficiencies. Asia has largest number of malnourished children in the world and basing on this fact Govt. of India also started "Mid day meal" programme which covers millions of children with major objective of improving the nutritional of children ${ }^{15}$. In order to improve nutritional status of children this has been strengthened from time to time. There is still a high prevalence of malnutrition despite mid day meal program running since decades. About $70 \%$ of children are underweight $32 \%$ are stunted and $70 \%$ subjects are anemic $\& 63 \%$ in a study by Patel, B.H. saxena, D. Singhal et al (2009) ${ }^{16}$. Presence of degree of anemia and $\mathrm{Hb} \%$ status can be estimated clinically by careful physical examination which has been confirmed by Patel et al ${ }^{13}, \&$ Strobach, R.S. Sharonk et al (1998) ${ }^{16}$.

The data on prevalence of micronutrient deficiencies related to Iron, Iodine and vitamin A could be elicited from clinical examination of children. Clinical symptoms of anaemia were visible in $32 \%$ of children which is similar to the study conducted by Rachana Bhaik, Uma Iyer, et al where it is $33.5 \%{ }^{17}$. Vitamin A deficiency was evident in $6 \%$ of children but $8.12 \%$ in Rachana study. The signs of iron deficiency were pale tongue, brittle nails, pale skin, angular stomatitis, fatigue and pallor. However in our study, there was no scope to rule out the other causes of anaemia. Pallor symptoms were most evident $80 \%$ which is similar to the study by Rachna et al where it is $78.3 \%$. Those that are identified for vitamin A deficiency had predominantly conjunctival xerosis $(60 \%)$.

CONCLUSIONS: Within the limitations of our study we found that in spite of marked decrease in severe malnutrition in school going children, mild to moderate malnutrion still a significant problem in school going children. Even though there is a reasonable decline in macronutrient deficiency, micronutrient deficiency is widely prevalent especially iron deficiency anemia in rural population of Andhra Pradesh.

\section{REFERENCES:}

1. Tracking the progress - development priority United Nations Children's Fund (UNICEF) November 2009 p3 
2. http://www.who.int/nutrition/topics/ida/en(accessed March 29, 2013)

3. Global Alliance for Improved Nutrition [GAIN], 2007

4. Report from Department for International Development, UK, 2008.

5. International Institute for Population Sciences (IIPS) \& ORC MACRO: National Family Health Survey (NFHS-3), 2005-06: India. Volume I. Mumbai: IIPS; 2007

6. Mason, J.B (2003) At least one third of poor countries diseases burden is due to malnutrition: diseases control priorities project: working paper no.1, March 2003.

7. National nutrition monitoring Bureau report on diet and nutritional status of adolescent, National Institute of Nutrition, India, 2002

8. Directions in Development. Repositioning nutrition as central to development -A strategy for long scale action. (2006)World Bank.

9. Kotecha, P.V. (2008) Micronutrient malnutrition in India: Let us say "no" to it. Indian J community Med; 33:9-10

10. WHO, information series on school health, document 13, Malaria prevention and control: An important responsibility of a health promoting school, 2007

11. WHO: Iron deficiency anaemia: assessment, prevention and control, guide for programme managers WHO/NHD/01.3 Page 30.

12. Bhoite Rachana, Iyer Uma Magnitude of Malnutrition and Iron Deficiency Anemia among Rural School Children: An Appraisal SCI. VOL 2(2) 2011: 354-361

13. Strobach, R.S. Sharonk et al .The value of physical examination in the diagnosis of anaemia. Arch. Intern Med ; 148 (4) ; 831-832.

14. Nutrition sub-comittee of the Indian Academy of Paediatrics. Report of Convener. Indian Pediatrics. 1972; 7: 360.

15. Nutritional support to education. Mid day meal program status notes from states, 1995.

16. Patel, B.H. Saxena, D. Singhal et al (2009), Intervention of Iron and Folic acid in school children. J. Hum. Eol. 25(1) ; on urban school children of Gujarat

17. Rachana Bhaik, Uma Iyer .Magnitude of Malnutrition and Iron deficiency anemia among Rural School Children ; An Appraisal Asian J. Exp. Biol. Sci. Vol 2 (2) 2011 ; 354-361.].

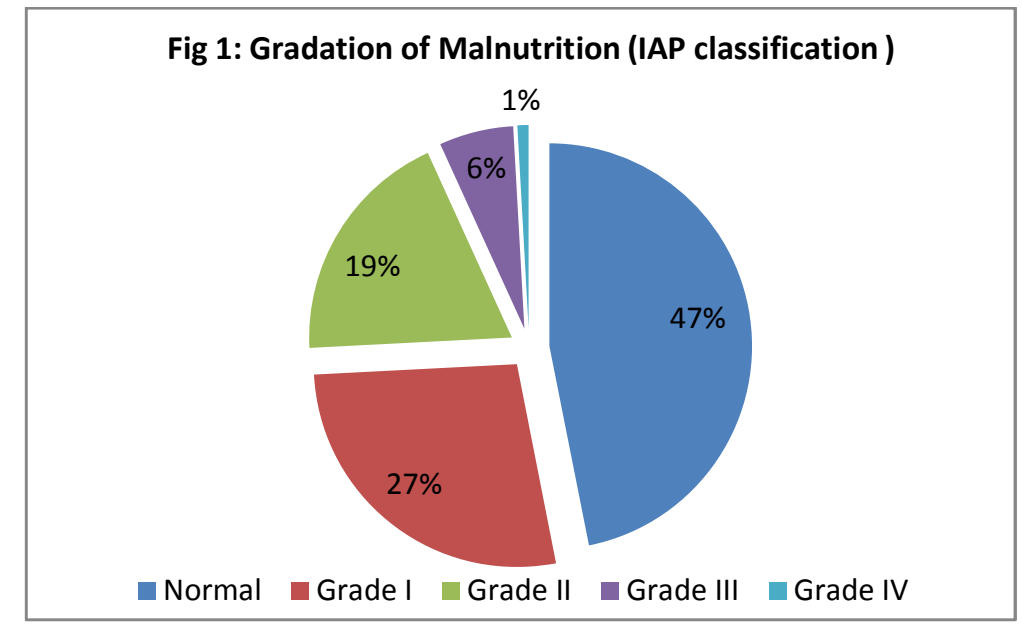

